\title{
The Interactive Effect of Organizational Identification and Organizational Climate on Employees' Taking Charge Behavior: A Complexity Perspective
}

\author{
Yun Liu, ${ }^{1}$ Lingjuan Chen $\mathbb{D}^{2},{ }^{2}$ Liangjie Zhao, ${ }^{3}$ and Chengai Li $\mathbb{D}^{4}$ \\ ${ }^{1}$ School of Business Administration, Shanghai Lixin University of Accounting and Finance, Shanghai 201620, China \\ ${ }^{2}$ School of Foreign Languages, Guangzhou College of Technology and Business, Guangzhou 510850, China \\ ${ }^{3}$ Business School, Southwest Minzu University, Chengdu 610041, China \\ ${ }^{4}$ Business School, Zhejiang Wanli University, Ningbo 315100, China
}

Correspondence should be addressed to Chengai Li; lichengai1979@zwu.edu.cn

Received 1 May 2021; Accepted 22 June 2021; Published 28 July 2021

Academic Editor: Lei Xie

Copyright ( $\odot 2021$ Yun Liu et al. This is an open access article distributed under the Creative Commons Attribution License, which permits unrestricted use, distribution, and reproduction in any medium, provided the original work is properly cited.

\begin{abstract}
In the view of complexity theory, the emergency behavior of individual is nonlinear and influenced not only by individual variables but also by many other environmental variables. Based on complexity perspective, this article explored why employees' taking charge behavior occurs in organizations from a multilevel approach. Specifically, this study has explored the cross-level interactive effect of organization-level factor (organizational justice climate and psychological safety climate) and individual-level factor (organizational identification) on employees' taking charge behavior. Using a total of 806 valid matching questionnaires from 91 firms in China, this study found that first, organizational identification is positively related with employees' taking charge behavior. Second, distributive justice climate positively moderates the influence of organizational identification on employees' taking charge behavior. Third, psychological safety climate negatively moderates the influence of organizational identification on employees' taking charge behavior. According to our results, organizational policies and practices should be made to foster employees' identification with the organization, to construct a fair environment within the organization, and to convince employees that taking charge behavior will not entail political risks, especially for those employees with low organizational identification.
\end{abstract}

\section{Introduction}

Organizations are complex adaptive systems in which organizational culture and climate promote the interactions among individuals, teams, and groups, and in turn the ideas, attitudes, and adaptive behaviors emerge from those interactions of their members [1, 2]. Employees' behaviors usually have their determinants at multiple levels (individual, group, and organization level), while most organizational behavior studies have typically analyzed only at one level [3]. Research conducted at a single level often ignores the fact that organizational dynamics result from multilevel interactions. For example, employees in an organization will not only make judgments based on their rational expectations, employees' behavior choices are highly influenced by local relationships, and the majority state in the organization has a significant effect on individuals [4]. Although singlelevel approaches have their own advantages, there is a knowledge gap in how multiple levels interact with one another and what implications they bring on organizational behavior. Moreover, in the view of complexity theory, the emergency behavior of individual is nonlinear and influenced not only by individual variables but also by many other environmental variables [5]. However, organizational researchers have seldom used multilevel analysis to achieve a bigger picture of organizational dynamics, which results in an incomplete understanding of multilevel interactions and their consequences [3]. So, this paper will use a multilevel approach to study employees' extra-role behavior.

All along, the importance of employees' extra-role behaviors to the competitiveness of corporations has been generally emphasized by scholars [6]. According to whether 
behavior is helpful to maintain interpersonal relationship, Van Dyne et al. [7] classified extra-role behaviors into two categories: affiliative behavior and challenging behavior. Affiliative behavior is intimate, cooperative, and noncontroversial and tends to consolidate or maintain interpersonal relationships, such as helping behavior; while challenging behavior is change-oriented, controversial, and emphasizing the reform of the status quo, which may damage the relationship with other people, such as voice behavior.

Morrison and Phelps [8] have proposed another example of challenging extra-role behavior, namely, taking charge, which means individual employees dedicate voluntary and constructive efforts to effect organizationally functional change with respect to how work is executed within the contexts of their jobs, work units, or organizations. Although they are both challenging extra-role behaviors, taking charge behavior is different from voice behavior. Voice behavior focuses on information collection and suggestions around problems in the work situation, while the remarkable characteristic of taking charge behavior is to make efforts to initiate and implement change; that is to say, it is not only to make suggestions [9]. Scholars have discussed a lot about voice behavior (see a review of [10], while taking charge behavior has received little attention.

Since Morrison and Phelps [8] put forward this concept, scholars have made some explorations on the influencing factors of taking charge behavior. These influencing factors can be classified into three levels: individual, leadership, and environmental level. At the individual level, factors, such as self-efficacy and felt responsibility [8], conscientiousness in Big Five [11], psychological contract breach [12], and propensity to trust and exchange ideology [13], have been found to positively predict the taking charge behavior of employees. At the leadership level, factors, such as ethical leadership [14], leader inclusiveness [15], LMX [16], empowering leadership $[17,18]$, transformational leadership $[19,20]$, and self-sacrificial leadership [21], have strong impact on employees' taking charge behavior through psychological empowerment, trust in leader, and identification with leader, and other mediating variables. At the environmental level, factors, such as top management openness [8], distributive justice and procedural justice [11], control types [13], idiosyncratic deals [22], job insecurity [23], and perceived organizational support [24], have significant predictive effect on employees' taking charge behavior.

According to the complexity theory, individual behavior in an organization is best understood as the result of an interactive process that happen between contextual factors and personal characteristics. Yet, the researchers above have tended to focus on either personal or situational predictors, respectively, and they rarely explore the interactive effect of both influencers on employees' taking charge behavior. Based on complexity perspective, this article explores why taking charge behavior occurs in organizations from a multilevel approach. Specifically, we explore the cross-level interactive effect of organization-level factor (organizational justice climate and psychological safety climate) and individual-level factor (organizational identification) on employees' taking charge behavior.
The rest of the article is organized as follows: in Section 2, the theoretical framework is proposed and a literature review is conducted to highlight the theoretical contributions of this study. In Section 3, research hypotheses are proposed. Section 4 details the research methodology, followed by the empirical analyses and results in Section 5. In Section 6, managerial implications are discussed, and the suggestions for future research are put forward.

\section{Research Framework}

In a word, this study is of great significance to the theoretical development of taking charge behavior by exploring the direct effect of organizational identification on employees' taking charge behavior, the cross-level direct effect of distributive justice climate and psychological safety climate on employees' taking charge behavior, and the cross-level moderating effect of distributive justice climate and psychological safety climate between organizational identification and employees' taking charge behavior. Our research model is as follows, see Figure 1.

In Figure 1, organizational identification is an individual-level variable, representing an individual influencing factor which has direct effect on the dependent variable. Distributive justice climate and psychological safety climate belong to organizational-level variables, representing environmental factors which have cross-level direct effect on the dependent variable, respectively. At the same time, distributive justice climate and psychological safety climate cross-levelly moderate the impact of organizational identification on the dependent variable, respectively.

Organizational identification refers to the individual perception of oneness with or belongingness to an organization, and it reflects the extent to which an employee defines himself/herself with reference to his/her organizational membership or the extent to which an employee integrating his/her social identity with organizational identity [25]. A variety of organizationally relevant outcomes have been found to be highly correlated with organizational identification, such as innovations, job involvement, in-role performance, and extra-role performance, turnover intentions, etc. [26]. However, few people have tested the impact of organizational identification on employee's taking charge behavior. So, Fuller et al. [27] suggested that, given that organizational identification was found to be positively related to voice behavior, future research should investigate the extent to which it is related to other change-oriented behavior such as taking charge behavior. This study attempts to explore the impact of organizational identification on taking charge behavior, so as to fill the gap. This is the first theoretical contribution of this study.

The literature on organizational justice shows that fair organizational environment can help to induce employees to show extra-role behavior, and unfair organizational environment will reduce employees' desire to engage in them. So, the first environmental factor we considered in our study is organizational justice climate. Organizational justice climate is a collective cognition or a shared perception held by 


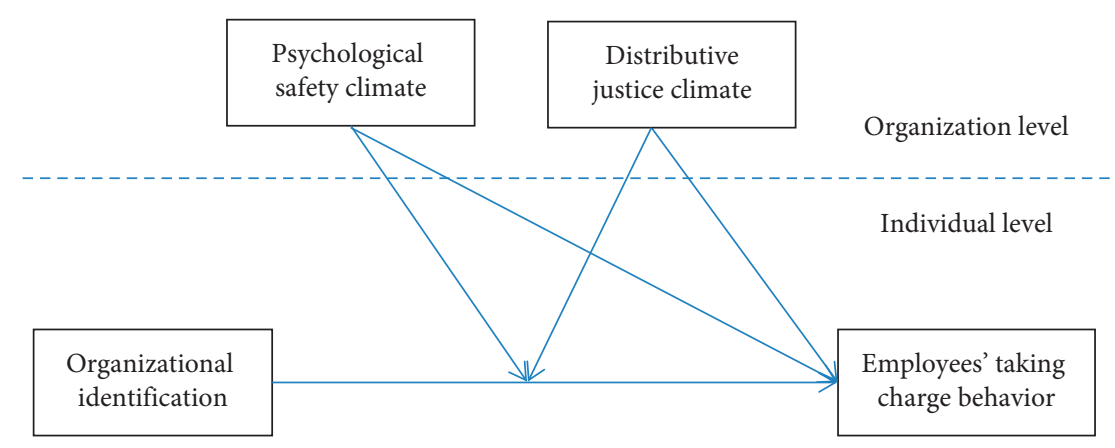

FIGURE 1: Research framework.

organizational members together about to what extent they are fairly treated by organizational authorities [28]. Organizational justice climate is different from individual justice perceptions. Individual justice perceptions are personal assessments of fair treatment by the organization they work for, while organizational justice climate refers to consensual collective cognitions, often represented by aggregated justice judgments of employees in the organizations [29]. Some scholars suggest that the collective evaluation of fair treatment by an organization may account for unique variance in important outcomes [30]. For example, a few cross-level studies demonstrate that justice climate has incremental validity in predicting individual-level attitudes and behavior beyond individual-level justice perceptions $[28,31]$. However, these studies focus more on the impact of organizational justice on affiliative extra-role behaviors, and few studies explore whether employees who are treated fairly have the motivation to perform challenging extra-role behaviors [11]. Therefore, this study will fill in this gap by exploring the cross-level impact of organizational justice climate on taking charge behavior. This is the second theoretical contribution of this study.

On the other hand, it is generally believed that organizational justice consists of three distinct but related components: distributive, procedural justice, and interactive justice [32]. Distributive justice refers to the perceived fairness of outcome distributions or allocations; procedural justice refers to the perceived fairness of the decisionmaking procedures used to determine the distribution of the outcome; interactive justice refers to the interpersonal treatment of organizational members in the process of implementation of organizational procedures. Because interactive fairness usually occurs between leaders and members, it is rarely concerned by scholars in organizational studies. Although scholars generally focused on the impact of procedural justice on employees' attitudes and behaviors, Lind and Tyler [33] argued that distributive justice judgments are likely to be more influential than procedural justice judgments in determining overall fairness judgments. Consistent with this argument, Conlon [34] found that distributive justice explained more variance in grievant evaluations of authorities (an appeal board) than did procedural justice. Tremblay et al. [35] also reported that the relationships with pay satisfaction and organizational satisfaction were stronger for distributive justice than procedural justice. Moreover, in the countries with collectivism culture, the decision-making process itself is not very transparent, so employees do not have high expectations for procedural fairness, and they tend to pay more attention to the fairness of distribution [36]. Therefore, we will not choose procedural justice climate but distributive justice climate as an environmental factor in this study.

Another environmental factor we considered in our study is psychological safety climate. Psychological safety climate was first studied at team level. Edmondson [37] put forward the concept of team psychological safety climate which is defined as shared perceptions that the team is safe for interpersonal risk taking. Later, Baer and Frese [38] defined the psychological safety climate at the organizational level, which refers to the shared perception of organizational members on "organizational policies or procedures that encourage open and trusted interpersonal interaction in the working environment." No matter at what level the concept is defined, psychological safety climate describes an organizational work environment in which employees can express their opinions boldly without fear of rejection or punishment. Psychological safety climate as an antecedent has been shown to correlate with firm performance [38], learning behaviors [37, 39], team member performance [40], and so on, but few scholars have studied the influence of psychological safety climate on employees' taking charge behavior. Chiaburu and Baker [13] pointed out that organizational culture, team atmosphere, and other predictive variables at the organizational or team level may also affect employees' taking charge behavior, which should be paid more attention. In order to fill the gap, this study will examine the cross-level direct effect of psychological safety climate on employees' taking charge behavior. This is the third theoretical contribution of this study.

\section{Hypotheses}

3.1. The Direct Effect of Organizational Identification. Based on social identity theory [41] and self-categorization theory [42], organizational identification has been defined as the employees' perception of oneness or belongingness to the organization where they work [25]. Although some scholars argued that there are two forms of organizational identification: situated identification (triggered by situational cues and thus is more temporary and unstable) and 
deep identification (a more fundamental connection between individual and collective and thus is stable and last), e.g., [43], Ashforth et al. [44] still insisted that organizational identification should be regarded as a more or less stable quality that transcends specific situations, and as a root or deep or stable construct. According to Ashforth and Mael [25], organizational identification is not an attitude concept (such as organizational commitment and job satisfaction), but a perceptual cognitive concept. To identify with an organization, there is no need to show any specific behavior or emotional state towards the organization, and an employee need only perceives himself or herself as psychologically intertwined with the fate of the organization.

According to social identity theory, part of the reason why individuals identify with an organization is to enhance self-esteem [45, 46]. A desire for self-enhancement motivates people to identify with the organization that excel other organizations [47]. By identifying with an organization, a person integrates his or her personal identity with organizational identity, the identity boundary between individual and organization becomes blurred, and then the salient attributes of that organization can be used to define him or herself, so as to gain a sense of self-esteem. Therefore, the strongly organizational identifiers usually hope the organization they identify with has a higher status and attractiveness than those compared organizations [48]. They also hope that the organizations they identify with continue to improve and have a greater competitive advantage in front of their competitors [49]. For strong identifiers, voluntarily helping the organization achieve its goal is important because the organization's goal is theirs as well. Therefore, it is a quite nature and common thing for them to dedicate voluntary and constructive efforts to effect organizationally functional change. The preceding discussion leads to the following hypotheses:

$\mathrm{H} 1$ : organizational identification is positively related with employees' taking charge behavior.

3.2. The Cross-Level Direct Effect and Cross-Level Moderating Effect of Distributive Justice Climate. A variety of employee attitudes and behaviors have been widely found to be influenced by perceptions of justice or fairness in the workplace [50]. As an old form of fairness, distributive justice refers to the perceived fairness of decision outcomes and has its roots in research on equity theory [51]. When an individual believes that the outcomes such as rewards or promotions he or she gets from the organization is fair, it is a signal that an individual's abilities and contribution are valued by the organization. According to the principle of reciprocity, when one is perceived as a valued member of an organization, he or she is more likely to demonstrate behaviors to help the organization thrive, as a form of social exchange [11]. Distributive justice has been shown to be significantly related to employee work-related attitudes and behaviors such as outcome satisfaction, system and agentreferenced evaluation of authorities, job satisfaction, organizational commitment, trust, and OCB [52]. So, we believe that fair rewards and recognition of their contributions will encourage individuals to engage in behaviors aimed at triggering positive changes in the organization. Moreover, the existing cross-level justice studies demonstrate that justice climate has incremental validity in predicting individual-level attitudes and behavior beyond individual-level justice perceptions [28]. Therefore, we have reason to believe that distributive justice climate has a positive predictive effect on employees' taking charge behavior. The following assumptions are proposed:

$\mathrm{H} 2 \mathrm{a}$ : distributive justice climate is positively related with employees' taking charge behavior.

According to the group engagement model [53], there are at least two different status evaluations about the groups can be made by employees to shape identification with that group: the group's status in the eyes of those outside the group and his or her own status in the eyes of others within the group. The group's status in the eyes of those outside the group has been indicated as "pride," and the perception of one's relative status within the group has been indicated as "respect." That is, people will be more highly motivated to merge their identity with a group when the group has high status (pride), when they feel that they have status in the group (respect), or both [53]. In the group engagement model, procedural justice judgments, distributive justice judgments, and outcome favorability have all been perceived as antecedents of employees' identity assessments, which implies that a sense of distributive justice helps to enhance employees' organizational identification. The group engagement model also suggests that "pride" will be particularly linked to mandatory-required behavior, whereas "respect" will be linked especially strongly to discretionaryvoluntary behavior [53].

On the basis of the group engagement model, Fuller et al. [27] further demonstrated that the status of the organization (pride or prestige) and the individual's status within it (respect) have different antecedents. They specially pointed out that high commitment management (HCM) practices, such as recognition by top management, opportunities for extensive training/development, participation in decisionmaking and problem solving, and pay for performance, are likely to be viewed by an employee as a signal or cue indicating that he or she is valued and respected within the organization, and should make independent contributions to an individual's overall evaluation of his or her status within the organization (i.e., respect). In a sense, all these HCM practices constitute a fair organizational environment, which is conducive to the formation of employees' perception of distribution fairness. This means that a perception of distributive fairness is beneficial to employees' judgment about "respect," thus enhancing his or her organizational identification.

From the above discussion, we can draw a conclusion that those highly identifiers exposing under a context with high distributive justice climate will engender a positive judgment of one's relative status within the group, thus further enhancing their identification with the organization, and therefore perform more cooperative behavior and engagement in organization. In another word, under a high 
distributive justice climate, the effect of organizational identification on employees' taking charge behavior will be strengthened. So, the following hypothesis is proposed:

H2b: distributive justice climate will positively moderate the influence of organizational identification on employees' taking charge behavior. In another word, the positive effect of organizational identification on employees' taking charge behavior will increase with the increase of distributive justice climate in an organization.

\subsection{The Cross-Level Direct Effect and Cross-Level Moderating} Effect of Psychological Safety Climate. Morrison and Phelps [8] argued that employees will weigh anticipated risks against anticipated benefits when deciding whether to engage in taking charge behavior. Taking charge behavior has potential risks, such as a damaged reputation if the initiative fails or disapproval if it is seen as inappropriate or threatening. According to this, employees will be less likely to engage in taking charge behavior if they fear that doing so will harm their images or bring them other losses. Therefore, employees' psychological safety is very important to improve their motivation to engage in taking charge behavior.

Psychological safety is the perception of employees that their self-image, status, and career will not suffer negative consequences when they employ and show themselves in work context [54]. Psychological safety affects employees' internal motivation to shape individual roles, and when employees experience more psychological safety, they will make higher work engagement [37]. Empirical studies also found that psychological safety helps to explain why employees speak up with suggestions for organizational improvements [55], and take initiative to engage process innovation [38].

Kahn [54] further pointed out that psychological safety was associated with elements of social systems that created more or less nonthreatening, predictable, and consistent social situations in which to engage. It implies that it is necessary to build a supportive organizational environment conducive to employees' psychological safety. Many studies proved that psychological safety climate is just such an organizational environment. For example, employees under high-level psychologically safe organizational climate feel easy and relaxed in taking interpersonal risks and are encouraged to propose new ideas, openly discuss problems, and proactively approach work [38]. Psychologically safe team climates mitigate team members' fears of social rejection or disapproval when speaking up, helping, or engaging in other social interactions in which there is the potential to be judged or humiliated by other team members [37].

Based on the above analysis, we believe that psychological safety climate can help employees gain a sense of psychological safety, so they are more willing to engage in taking charge behavior. Then, the following assumptions are put forward:

H3a: psychological safety climate is positively related with employees' taking charge behavior.
Yet, what does psychological safety climate mean to those strong organizational identifiers?

Ashforth and Mael [25] argued that the concept of identification is characterized by the following attributes: (1) identification describes only the cognition of oneness, not the behaviors and affect that may serve as antecedents or consequences of the cognition; (2) identification tend to occur even in the absence of strong leadership or member interdependency, interaction, or cohesion; (3) identification can persist tenaciously even when group affiliation is personally painful, other members are personally disliked, and group failure is likely; (4) identification maintains even if in situations involving great loss or suffering, missed potential benefits, task failure, and expected failure; (5) an organizationally identified employee, as a "microcosm of the organization" is likely to have attitudes and take actions that benefit the whole organization rather than benefitting individual self-interest.

The above characteristics of identification implied that there is no need for those strong organizational identifiers to rely on psychological safety to engage in taking charge behavior. Often, the strong organizational identifier wants to be a prototypical member of a particular organization, and his or her basic motivation to identify is the reputation and status of the organization and the self-esteem that derived from interorganizational comparisons [25]. So, the main purpose of engaging in taking charge behavior for them is to improve the reputation, status, and competitiveness of the organization they belong to. Usually, for those strong organizational identifiers, acting on behalf of the organization is tantamount to acting on behalf of themselves [56]. That is to say, although a better psychological safety climate in organization helps to improve the enthusiasm of ordinary people to engage in taking charge behavior, it has little influence on the enthusiasm of strong identifiers to engage in such behavior, because their intention to challenge the status quo is not affected by psychological safety.

However, when the psychological safety climate in the organization is relatively low, it is a different scene. Under a poor psychological safety climate, owing to fear and worry, the ordinary people in organization are often hesitant to engage taking charge. In this case, the strong organizational identifier will feel more obliged and responsible to optimize business operation to help the organization move forward. Because their fate is intertwined with the fate of the organization, the success or failure of an organization is equal to their success or failure. In another word, the poorer the psychological safety climate in an organization is, the more likely the strong organizational identifiers are to engage in taking charge behavior. Accordingly, we propose the following assumptions:

H3b: psychological safety climate will negatively moderate the influence of organizational identification on employees' taking charge behavior. In another word, the positive effect of organizational identification on employees' taking charge behavior will increase with the decrease of psychological safety climate in an organization. 


\section{Method}

4.1. Samples. Because this study needs to conduct a crosslevel analysis between the organizational level and the individual level, it needs to investigate a large number of firms, so the investigation task is very difficult. For this reason, we asked the on-the-job undergraduate students of a distance education university in Shanghai to help us and asked them to collect questionnaires in the corporations where they work. These on-the-job students are located in most provinces and cities in China. They are from different corporations and have rich working experience. After our persuasion, 91 on-the-job students are willing to serve as investigators of this study. These students come from 91 different firms distributed in most industries and cities in China. The questionnaire consists of two separate documents, $\mathrm{A}$ and $\mathrm{B}$. The content of document $\mathrm{A}$ includes control variables (such as gender, age, tenure, and position), organizational identification, perception of distributive justice, and psychological safety; the content of document B includes employees' taking charge behavior.

The investigation process is as follows: first, we train those on-the-job undergraduate students (as investigators) online. The training content includes questionnaire structure, how to send out and collect questionnaires, and the matters needing attention in the process of the survey. Secondly, we ask each investigator randomly selects some of his or her colleagues as the respondents. Thirdly, questionnaire A with a cover letter indicating the purpose of the investigation was sent to all the selected respondents through various methods such as emails and physical mails. At the same time, the investigators filled in questionnaire B according to the respondents' daily behavior. Lastly, once the questionnaire A returned from one respondent, corresponding questionnaire $\mathrm{B}$ will be merged with it to form a matched questionnaire.

This arrangement can prevent common method variance biases because the data of control variables, independent variables, and moderating variables are from the investigator's colleagues (respondents), while the data of result variables are from the investigators themselves. At last, a total of 806 valid matching questionnaires were collected from 91 firms. The number of respondents in each firm ranges from 4 to 13 . The distribution of demographic characteristics of the sample is as follows: of the final sample, $39.0 \%$ are under 25 years old, $4.5 \%$ are over 41 years old, and $56.5 \%$ are $26-40$ years old; most of them are well educated, $11.8 \%$ have high-school education, $85.4 \%$ have college or bachelor degree, and $2.8 \%$ have graduate degree or above; among the respondents, $4.3 \%$ have tenure of 1 year below, $95.7 \%$ have tenure of more than 2 years, $73.4 \%$ of the respondents are ordinary employees, $26.6 \%$ are supervisors or department managers, $41.5 \%$ of the respondents are male, and $58.5 \%$ are female.

\subsection{Measurement}

4.2.1. Control Variables. In the empirical studies on taking charge behavior, scholars are used to take demographic characteristics of employees as control variables. For example, Moon et al. [11] used gender and job tenure (measured in years) as control variables in their study. Morrison and Phelps [8] used position level, job tenure, gender, and age as control variables in their study. Demographic characteristics such as job type, age, gender, education, and organizational tenure were used as control variables in the study of Burnett et al. [24]. Therefore, this study takes age, education, tenure (organizational tenure), and rank (position level) as control variables. The coding of control variables is shown in Table 1 . For example, age is set as a 5-value variable, below 25 years old is coded as 1 , between 26 and 30 years old is coded as 2, and so on, and over 40 years old is coded as 5 .

In the above control variables, except for the variable of rank including 3 grades, the other variables include 5 grades. For the latent variables in this study, all scales utilized a fivepoint response format ranging from strongly disagree (1) to strongly agree (5). Because the survey was conducted in China, so we need to translate the English scales into Chinese. Using the procedures established by Brislin [57], all the English scales were translated and back-translated to ensure the Chinese translation was consistent with the English meaning.

4.2.2. Organizational Identification. Based on the Mael and Ashforth [58] six-item scale (e.g., when I talk about this organization, I usually say "we" rather than "they"), we used "back translation" to form the Chinese version of the organizational identification scale. We used the 806 data to test the reliability, and Cronbach's alpha for this scale was 0.9032, which shows that the organizational identification scale has good measurement reliability.

4.2.3. Distributive Justice Climate. Distributive justice climate is an organization-level variable, and its measurement value is obtained through the integration of the distributive justice perception of individual employees. Ramamoorthy and flood [59] developed a 5-item scale to measure employees' perception of distributive justice (e.g., I am fairly rewarded for the responsibilities I take on). Based on this scale, a Chinese version was formed through "back translation." We used the 806 data to test the reliability, and Cronbach's alpha for this scale was 0.9089 , which shows that the distributive justice perception scale has good measurement reliability.

4.2.4. Psychological Safety Climate. Psychological safety climate is an organization-level variable, and its measurement value is obtained through the integration of the psychological safety of individual employees. Edmondson [37] developed a 7-item scale to measure employees' psychological safety. A sample item is "In our company, one is free to take risks." We used "back translation" to turn the scale into a Chinese version. We used the 806 data to test the reliability, Cronbach's alpha for this scale was 0.8804 , which shows that the psychological safety perception scale has good measurement reliability. 
TABLE 1: The coding of control variables.

\begin{tabular}{lccccc}
\hline Variable/code & 1 & 2 & 3 & 4 & 5 \\
\hline Age & Under 25 years old & 26-30 years old & $31-35$ years old & 36-40 years old & Over 40 years old \\
Education & Junior high school & High school & Junior college & Undergraduate & Postgraduate \\
Tenure & Less than 1 years & $1-2$ years & $2-5$ years & 5-10 years & More than 10 years \\
Rank & Front-line staff & Supervisor & Manager & & \\
\hline
\end{tabular}

4.2.5. Taking Charge Behavior. Taking charge behavior is an individual-level variable. We used the 10-item scale developed by Morrison and Phelps [8] to assess employees' taking charge behaviors as reported by their colleagues. A sample item is "This person often tries to adopt improved procedures for doing his or her job." Based on this scale, a Chinese version was formed through "back translation." We used the 806 data to test the reliability, Cronbach's alpha for this scale was 0.8979 , which shows that the taking charge behavior scale has good measurement reliability.

Then, we construct a first-order 1-factor confirmatory factor analysis model for each latent variable and use 806 data to fit the hypothetical factor model. The fitting indexes of all models are shown in Table 2. Each model fits the data well, which shows that the scale of research variable has good structural validity.

\section{Results}

In multilevel data analysis, scholars usually use the withingroup inter-rater reliability (Rwg) and reliability of score within group (ICC(1)) or reliability of mean group score (ICC(2)) to judge whether individual ratings can be aggregated into collective-level variables. Generally speaking, when Rwg is greater than 0.7 [60], ICC (1) is greater than 0.05 and $F$ test is significant, and ICC (2) is greater than 0.5 [61], researchers can aggregate individual perceptions into collective climate.

In this study, 105 firms were investigated. Firstly, the Rwg coefficient for distributive justice and psychological safety of the respondents in the same firm were computed by SPSS 12.0 software. According to the principle that the Rwg value is greater than 0.7 , the data of 91 firms are valid. Among the $91 \mathrm{firms}$, the mean of Rwg value for distributive justice was 0.8416 , ICC (1) value was 0.2196 ( $F$ test was significant), and ICC (2) value was 0.7137 ; the mean of Rwg value for psychological safety was 0.8983 , ICC (1) value was 0.3197 ( $F$ test was significant), and ICC (2) value was 0.8063 . The results show that the scores of distributive justice and psychological safety can be aggregated into the scores of the distributive justice climate and psychological safety climate. All items were answered on a five-point scale, and the descriptive statistics of latent variables are shown in Table 3.

\subsection{HLM. Step 1: null model.}

Because our model assumes that employees' taking charge behavior is predicted by individual-level and organization-level variables together, so it must be confirmed that taking charge behavior has variance both at individual level and at organizational level.
Therefore, the first step is to use ANOVA to divide the variance of employees' taking charge behavior into intragroup and intergroup variance. The results of ANOVA showed that the intergroup variance $\left(\tau_{00}\right)$ is $0.06413(\chi 2=201.79877, P<0.001)$, indicating that the variance of taking charge behavior between groups was significant. In addition, the within-group variance $\left(\sigma^{2}\right)$ is 0.46210 , and the ICC $(1)=\tau_{00} /\left(\sigma^{2}+\tau_{00}\right)=0.122$, indicating that $12.2 \%$ of the variance of employees' taking charge behavior comes from the variance between groups, while $88 \%$ comes from the variance within the group. Because the dependent variable has significant intergroup variance, then we can test our hypotheses. The hypothesis test is completed in the following three steps, and the test results are shown in Table 4.

Step 2: testing the main effect of organizational identification.

First, we regressed taking charge behavior (dependent variable) on the individual-level independent variables (organizational identification) with control variables (age, education, tenure, and rank). In model $1, \gamma_{50}$ represents the influence coefficient of organizational identification on employees' taking charge behavior, which is used to test hypothesis 1 . The results of model 1 show that $\gamma_{50}=0.1783(P<0.001, t=5.996)$. So, hypothesis 1 is supported, and organizational identification is positively related with employees' taking charge behavior. $R^{2}$ of model 1 is 0.397 , which means $39.7 \%$ of intragroup variance can be explained by control variables and organizational identification. In addition, after control variables and organizational identification were entered into model 1 , intergroup variance $\left(\tau_{00}\right)$ is $0.0853(\chi 2=330.432$ and $P<0.001)$, and it indicates that there may be group-level factors in level-2, so we will go to Step 3 next.

Step 3: testing the direct effect of distributive justice climate and psychological safety climate.

Hypothesis $2 \mathrm{a}$ and hypothesis $3 \mathrm{a}$ argue that both distributive justice climate and psychological safety climate have a positive impact on employees' taking charge behavior.

In order to test hypothesis $2 \mathrm{a}$ and hypothesis $3 \mathrm{a}$, we add distributive justice climate and psychological safety climate to level-2 and estimate the model with intercept as the result variable. In model $2, \gamma_{01}$ and $\gamma_{02}$ represent the estimates of the effect of distributive justice climate and psychological safety climate on employees' taking charge behavior, respectively, after controlling age, education, tenure, rank, and organizational 
TABLE 2: Fitting index of confirmatory factor analysis of measurement tools.

\begin{tabular}{|c|c|c|c|c|c|c|}
\hline Model & $X^{2} / \mathrm{d} f$ & RMSEA & SRMR & NNFI & CFI & GFI \\
\hline Model 1: organizational identification & 4.18 & 0.075 & 0.031 & 0.97 & 0.98 & 0.96 \\
\hline Model 2: distributional justice perception & 3.423 & 0.075 & 0.047 & 0.96 & 0.97 & 0.98 \\
\hline Model 3: psychological safety perception & 4.32 & 0.082 & 0.052 & 0.92 & 0.95 & 0.91 \\
\hline Model 4: taking charge behavior & 4.2 & 0.085 & 0.067 & 0.91 & 0.93 & 0.86 \\
\hline
\end{tabular}

TABle 3: The descriptive statistics of latent variables.

\begin{tabular}{|c|c|c|c|c|c|}
\hline Variable & Number of samples & Minimum & Maximum & Mean & Standard deviation \\
\hline \multicolumn{6}{|l|}{ Level-1 } \\
\hline Organizational identification & 806 & 1.00 & 5.00 & 3.64 & 0.84 \\
\hline Employees' taking charge behavior & 806 & 1.30 & 5.00 & 3.70 & 0.72 \\
\hline \multicolumn{6}{|l|}{ Level-2 } \\
\hline Distributive justice climate & 91 & 1.80 & 4.82 & 3.41 & 0.52 \\
\hline Psychological safety climate & 91 & 2.19 & 4.76 & 3.51 & 0.52 \\
\hline
\end{tabular}

TABLE 4: HLM analysis with taking charge behavior as dependent variable.

\begin{tabular}{|c|c|c|c|}
\hline Variable & Model 1 & Model 2 & Model 3 \\
\hline \multicolumn{4}{|l|}{ Level-1 } \\
\hline Intercept $\left(\gamma_{00}\right)$ & $3.6959^{* * *}$ & $2.5783^{* * *}$ & $2.5783^{* * *}$ \\
\hline Age $\left(\gamma_{10}\right)$ & 0.0335 & 0.0323 & 0.0332 \\
\hline Education $\left(\gamma_{20}\right)$ & $0.1019^{* *}$ & $0.1022^{* *}$ & $0.1004^{* *}$ \\
\hline Tenure $\left(\gamma_{30}\right)$ & $0.0539^{*}$ & $0.0566^{*}$ & $0.0554^{*}$ \\
\hline $\operatorname{Rank}\left(\gamma_{40}\right)$ & $0.2027^{* * *}$ & $0.2017^{* * *}$ & $0.1991^{* * *}$ \\
\hline Organizational identification $\left(\gamma_{50}\right)$ & $0.1783^{* * *}$ & $0.1786^{* * *}$ & $0.2494^{* *}$ \\
\hline \multicolumn{4}{|l|}{ Level-2 } \\
\hline \multicolumn{4}{|l|}{ Cross-level main effects } \\
\hline Distributive justice climate $\left(\gamma_{01}\right)$ & & $0.1366^{*}$ & $0.1368^{*}$ \\
\hline Psychological safety climate $\left(\gamma_{02}\right)$ & & $0.1854^{*}$ & $0.1852^{*}$ \\
\hline \multicolumn{4}{|l|}{ Cross-level interaction effects } \\
\hline Distributive justice climate ${ }^{*}$ organizational identification $\left(\gamma_{51}\right)$ & & & $0.2177^{*}$ \\
\hline Psychological safety climate $*$ organizational identification $\left(\gamma_{52}\right)$ & & & $-0.2286^{* *}$ \\
\hline
\end{tabular}

identification in level-1. T-test of $\gamma_{01}$ can be used to test hypothesis $2 \mathrm{a}$, and $T$-test of $\gamma_{02}$ can be used to test hypothesis $3 \mathrm{a}$.

The results of model 2 show that $\gamma_{01}=0.1366, t=2.543$, and $P<0.05$, So, hypothesis $2 \mathrm{a}$ is supported. $\gamma_{02}=0.1854, t=2.075, P<0.05$, and hypothesis $3 \mathrm{a}$ is supported. $R^{2}$ of model 2 is 0.232 , which means $23.2 \%$ of intergroup variance of dependent variable can be explained by distributive justice climate psychological safety climate. In addition, $\chi^{2}(88)=270.404$ and $P<0.001$, indicating that the relationship between level-1 predictors and taking charge behavior was significantly different among different groups. Therefore, the next step is to test the moderating effect of distributive justice climate and psychological safety climate.

Step 4: testing the moderating effect of distributive justice climate and psychological safety climate.

Hypothesis $2 \mathrm{~b}$ argues that distributive justice climate will positively moderate the influence of organizational identification on employees' taking charge behavior, while hypothesis $3 \mathrm{~b}$ argues that psychological safety climate will negatively moderate the influence of organizational identification on employees' taking charge behavior.

In order to test the above interaction effect, we can use distributive justice climate and psychological safety climate as predictors of the $\beta$ coefficient of organizational identification, so as to know whether distributive justice climate and psychological safety climate can explain the variance of the $\beta$ coefficient of organizational identification. In model $3, \gamma_{51}$ represents the estimate of the interaction effect between distributive justice climate and organizational identification. $T$-test of $\gamma_{51}$ can be used to test hypothesis $2 \mathrm{~b}$. In model $3, \gamma_{52}$ represents the estimate of the interaction effect between psychological safety climate and organizational identification. $T$-test of $\gamma_{52}$ can be used to test hypothesis $3 \mathrm{~b}$.

The results of model 3 show that $\gamma_{51}=0.2177, t=2.444$, and $P<0.05$, indicating the interaction effect of distributive justice climate and organizational identification on the dependent variable is significant. So, hypothesis $2 b$ is supported. The results of model 3 show that $\gamma_{52}=-0.2286$, $t=-2.653$, and $P<0.01$, indicating the interaction effect of psychological safety climate and organizational identification on the dependent variable is significant. So, hypothesis $3 \mathrm{~b}$ is supported. 
The interaction effect of organizational identification and distributive justice climate on employees' taking charge behavior is shown in Figure 2. In Figure 2, the black solid line represents the effect of organizational identification on employees' taking charge behavior under the high level of distributive justice climate, and the black dotted line represents the effect of organizational identification on employees' taking charge behavior under the low level of distributive justice climate.

According to Figure 2, the slope of black solid line is positive and steep, indicating that when the level of distributive justice climate is high, organizational identification has a positive impact on employees' impact behavior, and the effect is significant. The slope of black dotted line is negative and gentle, indicating that when the level of distributive justice climate is low, organizational identification negatively affects employees' taking charge behavior, but the effect is not significant. In general, distributive justice climate positively moderates the effect of organizational identification on employees' taking charge behavior.

The interaction effect of organizational identification and psychological safety climate on employees' taking charge behavior is shown in Figure 3. In Figure 3, the black solid line represents the effect of organizational identification on employees' taking charge behavior under the high level of psychological safety climate, and the black dotted line represents the effect of organizational identification on employees' taking charge behavior under the low level of psychological safety climate.

According to Figure 3, the slope of black solid line is negative and gentle, indicating that when the level of psychological security climate is high, organizational identification negatively affects employees' taking charge behavior, but the effect is not significant. The slope of black dotted line is positive and steep, which shows that when the level of psychological safety climate is low, organizational identification has a positive impact on employees' taking charge behavior, and the effect is significant. Generally speaking, the psychological safety climate negatively moderates the influence of organizational identification on employees' taking charge behavior.

\section{Discussion}

6.1. Theoretical Implications. In practical terms, taking charge behaviors consist of adopting improved procedures for the job, changing how the job is executed in order to be more effective, or correcting a faulty procedure or practice [13]. Such behaviors are consistent with the more recent business imperatives of "getting off the treadmill" and are conducive to the self-improvement and development of corporations. In the past, few scholars have explored the antecedents of employees' taking charge behavior from the perspective of organizational identification. Our study has confirmed the positive effect of organizational identification on employees' taking charge behavior, thus filled this gap. Once identified with the organization, an employee usually shares the common fate with the organization, so he or she intrinsically performs taking charge behaviors to improve the organization's function. It is just the identity integration between them and the organizations (namely, identification) that make them voluntarily engage in taking charge behaviors. Our conclusion also confirms what the group engagement model [53] said, "Cooperation is driven, in other words, by the motivation to create and maintain a favorable identity."

In addition, our study has discussed the boundary conditions of the relationship between organizational identification and employees' taking charge behavior.

Firstly, our study found that organizational distributive justice climate positively moderate the relationship between organizational identification and taking charge behavior. This means that organizational justice climate acts as an environmental catalyst, amplifying the impact of organizational identification on employees' taking charge behavior. In other words, once an organizational identifier works in a fair environment, his organizational identification will be further enhanced, therefore more taking charge behavior will appear. This finding can be explained as follows. The literature proposed that not only the organization's status in society (such as attractiveness, distinctiveness, prestige, construed external image, etc.) but also the individual's status in organization (such as respect etc.) have been considered as the important antecedents of employees' organizational identification, because these factors help to enhance employees' self-esteem and self-image [62].The literature also proposed that organizational justice can enhance employees' organizational identification, because for employees, being treated fairly by the organization's authority equals being respected and valued [62]. Therefore, a fair organizational environment can make those organizational identifiers (those who have identified with the organization for other reasons) experience the feeling of being respected and valued, which further enhances their organizational identification. Our study has found the amplifying effect of distributive justice climate between organizational identification and taking charge behavior, which provided empirical support for the above proposition.

Secondly, our study found that psychological safety climate negatively moderates the relationship between organizational identification and taking charge behavior. Owing to the challenging and risky nature of taking charge behavior, it is generally believed that in an environment that can provide psychological safety, people are more likely to engage in taking charge behavior. That is also what Morrison and Phelps [8] proposed. Generally speaking, this statement is correct, because, when employees decide whether to engage in taking charge, they will trade off the expected cost and expected benefit of that behavior. Our research results showed that psychological safety climate has a positive direct impact on employees' taking charge behavior, which also provides support for the above conclusion. However, for a person who is highly identified with the organization, the positive effect of psychological safety climate on taking charge behavior will weaken or even disappear. The reasons can be explained as follows. According to the literature, an organizationally identified person will not consider personal interests when engaging in taking charge behavior, because 


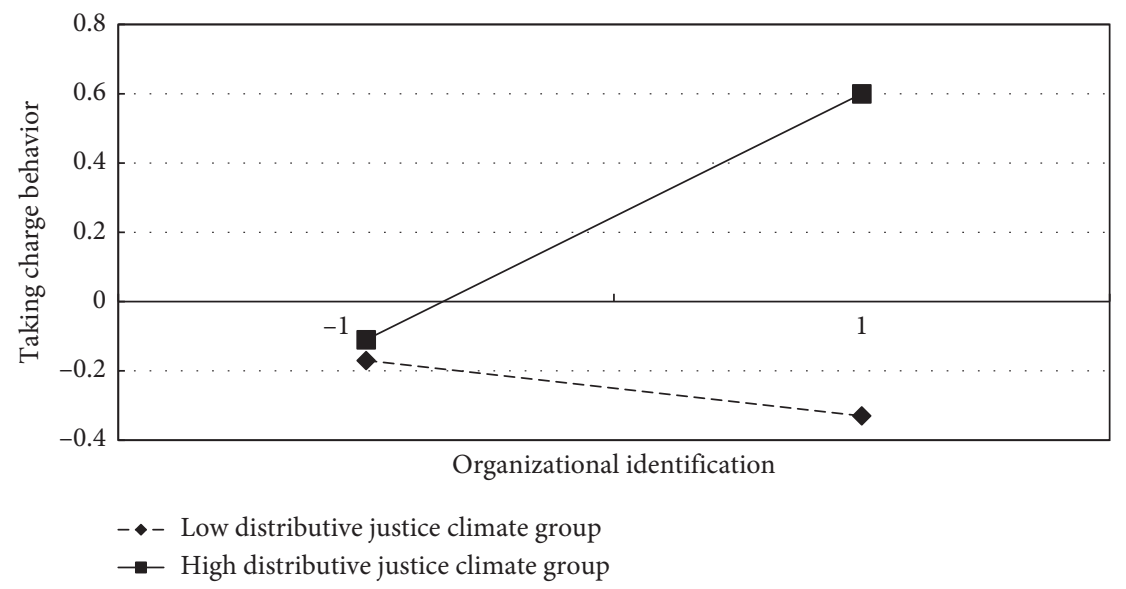

FIGURE 2: The interaction effect of organizational identification and distributive justice climate on employees' taking charge behavior.

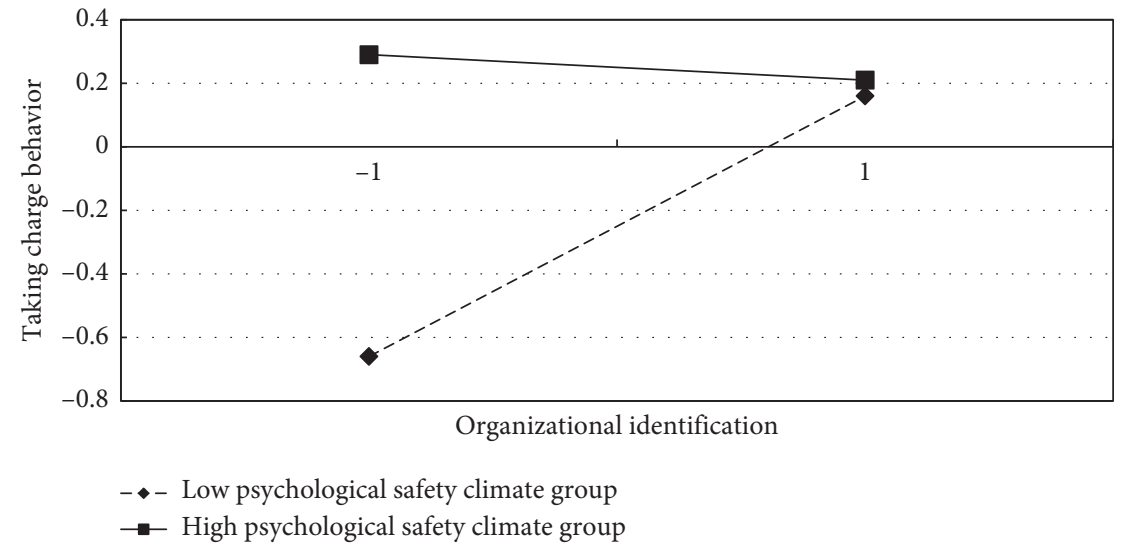

Figure 3: The interaction effect of organizational identification and psychological safety climate on employees' taking charge behavior.

identification maintains even if in situations involving great loss or suffering, missed potential benefits, task failure, and expected failure, and an organizationally identified employee, as a "microcosm of the organization" is likely to have attitudes and take actions that benefit the whole organization rather than benefitting individual self-interest [25]. That is to say, psychological safety is not a necessary condition for organizational identifiers to engage in taking charge behavior. They instinctively engage in such behaviors to change the functions of the organization, so as to increase the reputation and competitiveness of the organization, thus enhancing their own self-esteem and status. In particular, the worse the psychological safety climate, the more responsibility they feel to engage in taking charge. They perceive it as their mission to increase the reputation and competitiveness of an organization through taking charge, especially when no one else dares to challenge the status quo. In short, psychological safety may be a key environmental condition for a person with low organizational identification to engage taking charge behavior. However, for a person with high organizational identification, the lower the psychological safety perception, the more likely he or she is to engage in taking charge behavior, because she or he has the mission and original deep motive to change the bad environment. Our study has found buffering effect of psychological safety climate between organizational identification and taking charge behavior, which has a significant contribution to taking charge behavior research field.

6.2. Practical Implications. As no organization can foresee all environmental changes and potential accidents, the organizations are increasingly relying on employees to engage in proactive behavior to challenge the status quo, promote innovation, and initiate strategic change [63]. Staw and Boettger [64] also strengthened the importance of employees taking actions to correct wrong tasks or work roles. They believe that if the current role definition, procedures, or policies are inappropriate or ineffective, the most important thing for employees is to shift their extra-role efforts to change rather than maintain the status quo. So, it is very important for managers to take strategies to improve the enthusiasm of employees to engage in taking charge behavior.

According to our findings, employees with high organizational identification are more likely to engage in taking charge behavior. Therefore, organizational policies and practices should be made with the intent to foster employees' identification with the organization. The literature shows that the attractiveness, distinctiveness, prestige, construed 
external image that organizations get from society, and the status and respect that employees get in the company are key determinants of employees' organizational identification. Some human resource management practices, such as participation in decision-making, positive recognition by top management, performance-based reward system, and opportunities for extensive training, can be used to influence employees' perceptions of status and respect within the organization [27]. For example, managers can reduce the uncertainty of the reward system through multiple management strategies (such as improving the transparency of reward system), which will help enhance the organizational identification of employees.

Moreover, in order to improve the company's reputation, some public relation strategies should be used to communicate the company's achievements to internal employees and external stakeholders. Additionally, recruiting, socialization and training programs can incorporate information about the accomplishments of the organization [27]. From the perspective of complexity, feedback loops are the one of key factors that helps self-organizing systems operate effectively [65]. This means that communication is more effective in a complex adaptive system, and managers need to listen carefully to the voice of employees and avoid implanting control or pulling rank behavior during communication [66].

According to our findings, high level of distributive justice climate is conducive to improve the motivation of employees to engage in taking charge behavior. Distributive justice climate refers to the aggregated individual justice perceptions of organizational events and practices related with distribution results. Our results showed that organizational justice climate is the accelerator of organizational identification. People evaluate their identity and status in a particular group by the level of the respect that they are receiving from that group, the more they feel fair, the more they feel being respected, and the more they identify with the organization. Therefore, corporate policy and process should construct a fair environment within the organization. For example, one implication of complexity theory for organization procedure design is that firms should consider the elements of environmental setting and perceived fairness in penalty and reward system design [5].

According to our findings, as far as the motivation of taking charge behavior is concerned, although psychological safety climate has little influence on people with high organizational identification, it has significant influence on people with low organizational identification. High level of psychological safety climate is conducive to improve the motivation of employees with low organizational identification to engage in taking charge behavior. So, the company should construct an environment to convince employees that taking charge behavior will not be met with resistance or entail high political risks. When employees perceive that organizational policies support constructive efforts to bring about improvement, they may be more confident that taking charge will be effective and less concerned about potential costs [8]. Taking charge can only be achieved if strong climates for psychological safety exist in the organization, and for people to feel comfortable engaging in taking charge without fear of ridicule or punishment, managers must work to create a climate of psychological safety. For instance, the complexity lens implies that error-free systems are too rigid to coevolve with the environment [67]. Hence, managers should be deeply aware of the role of failure in organizational learning and adaptation and enhance psychological safety by building a corporate culture that embraces failure.

6.3. Limitations and Future Directions. Firstly, our study could be criticized for the small sample size. So, a lot of companies should be investigated as samples in future study. A second limitation of the research is that all the data were collected at roughly the same time. Thus, we are unable to make definitive causal conclusions based on our findings. Lastly, we use different sources to gather the data for the research variables, so the effect of common method bias on results can be alleviated. In this study, we use coworker's evaluation to measure outcome variable, and supervisor's evaluation can be used to measure outcome variables in future studies, to verify our results.

Future research can explore the influence of proactive personality on taking charge behavior. Proactive personality refers to the tendency of an individual to take initiative to change his external environment without the restriction of situational resistance [68]. Crant and Bateman [69] believe that individuals with proactive personalities prefer to challenge the status quo rather than passively accept their roles. They are good at finding and seizing opportunities, taking initiative actions, and persevere until their actions produce the expected results. They actively change the organization's goals and find and solve problems; they rely on themselves rather than others to influence the world around them. According to the definition of taking charge behavior, we may reasonably conclude that proactive personality has a positive impact on employees' taking charge behavior. However, we are not sure whether and how the influence of proactive personality on taking charge behavior is moderated by organizational justice climate and psychological safety climate. Therefore, this problem deserves the attention of future scholars.

Cooper and Thatcher [47] discussed self-concept orientations on employees' organizational identification. Selfconcept orientations are the general tendency to think of the self in terms of individual characteristics, role relationships, or group memberships [47]. Three self-concept orientations were defined, individualist orientation, relationist orientation, and collectivist orientation. Cooper and Thatcher [47] argued that collectivist orientation, which means the tendency of individuals to value groups and view themselves in terms of group memberships, increases the likelihood of work group and organizational identification. Therefore, the future research can take collectivist orientation as an independent variable to explore the impact of self-concept orientation on taking charge behavior.

Another important construct associated with organizational climate is climate strength. Schneider et al. [70] defined climate strength as the intragroup variance of 
climate perception. Research on climate strength suggests that individuals who operate in strong climates hold convergent expectations about how others will interact and behave, resulting in compliance and uniform behavior [40]. Therefore, climate strength may enhance the influence of climate on outcomes, because group consensus creates a strong situation, which makes it difficult for group members to deviate from consistent practices [70]. For instance, Schneider et al. [70] found that service climate was positively related to customer service quality in strong climates, but unrelated in weak climates. Therefore, the future research should explore the moderating effect of climate strength between psychological safety climate, organizational justice climate, and employees' taking charge behavior.

\section{Data Availability}

The data used to support the findings of this study are available from the corresponding author upon request.

\section{Conflicts of Interest}

The authors declare no conflicts of interest.

\section{References}

[1] P. Anderson, "Perspective: complexity theory and organization science," Organization Science, vol. 10, no. 3, pp. 216-232, 1999.

[2] M. Schneider and M. Somers, "Organizations as complex adaptive systems: implications of complexity theory for leadership research," The Leadership Quarterly, vol. 17, no. 4, pp. 351-365, 2006.

[3] J. Tasic, F. Tantri, and S. Amir, "Modelling multilevel interdependencies for resilience in complex organisation," Complexity, vol. 2019, Article ID 3946356, 23 pages, 2019.

[4] L. Zhang, Y. Xing, and S. Guo, "A model and complexity analysis of the relationship based on organizational justice and embeddedness theories," Complexity, vol. 2020, Article ID 6129840, 16 pages, 2020.

[5] P. W. Brodbeck, "Complexity theory and organization procedure design," Business Process Management Journal, vol. 8, no. 4, pp. 377-402, 2002.

[6] D. Katz, "The motivational basis of organizational behavior," Behavioral Science, vol. 9, no. 2, pp. 131-146, 1964.

[7] L. Van Dyne, L. L. Gummings, and J. M. Parks, "Extra-role behaviors: in pursuit of construct and definitional clarity," Research in Organizational Behavior, vol. 17, pp. 215-285, 1995.

[8] E. W. Morrison and C. C. Phelps, "Taking charge at work: extra role efforts to initiate workplace change," Academy of Management Journal, vol. 42, no. 4, pp. 403-419, 1999.

[9] S. K. Parker and C. G. Collins, "Taking stock: integrating and differentiating multiple proactive behaviors," Journal of Management, vol. 36, no. 3, pp. 633-662, 2010.

[10] E. W. Morrison, "Employee voice behavior: integration and directions for future research," Academy of Management Annals, vol. 5, no. 1, pp. 373-412, 2011.

[11] H. Moon, D. Kamdar, D. M. Mayer, and R. Takeuchi, "Me or we? the role of personality and justice as other-centered antecedents to innovative citizenship behaviors within organizations," Journal of Applied Psychology, vol. 93, no. 1, pp. 84-94, 2008.
[12] P. M. Bal, D. S. Chiaburu, and I. Diaz, "Does psychological contract breach decrease proactive behaviors? the moderating effect of emotion regulation," Group \& Organization Management, vol. 36, no. 6, pp. 722-758, 2011.

[13] D. S. Chiaburu and V. L. Baker, "Extra-role behaviors challenging the status-quo:validity and antecedents of taking charge behaviors," Journal of Managerial Psychology, vol. 21, no. 7, pp. 620-637, 2006.

[14] K. Lee, "Ethical leadership and followers' taking charge: trust in, and identification with, leader as mediators," Social Behavior and Personality: An International Journal, vol. 44, no. 11, pp. 1793-1802, 2016.

[15] N. Li, Q.-Y. Guo, and H. Wan, "Leader inclusiveness and taking charge: the role of thriving at work and regulatory focus," Frontiers in Psychology, vol. 10, pp. 1-9, 2019.

[16] T.-Y. Kim, Z. Liu, and J. M. Diefendorff, "Leader-member exchange and job performance: the effects of taking charge and organizational tenure," Journal of Organizational Behavior, vol. 36, no. 2, pp. 216-231, 2015.

[17] J. Qian, B. Song, Z. Jin, B. Wang, and H. Chen, "Linking empowering leadership to task performance, taking charge, and voice: the mediating role of feedback-seeking," Frontiers in Psychology, vol. 9, p. 2025, 2018.

[18] S.-L. Li, W. He, K. C. Yam, and L.-R. Long, "When and why empowering leadership increases followers' taking charge: a multilevel examination in China," Asia Pacific Journal of Management, vol. 32, no. 3, pp. 645-670, 2015.

[19] J. Li, S. Furst-Holloway, L. Gales, S. S. Masterson, and B. D. Blume, "Not all transformational leadership behaviors are equal: the impact of followers' identification with leader and modernity on taking charge," Journal of Leadership \& Organizational Studies, vol. 24, no. 3, pp. 318-334, 2017.

[20] N. Li, D. S. Chiaburu, B. L. Kirkman, and Z. Xie, "Spotlight on the followers: an examination of moderators of relationships between transformational leadership and subordinates' citizenship and taking charge," Personnel Psychology, vol. 66, no. 1, pp. 225-260, 2013.

[21] R. Li, Z.-Y. Zhang, and X.-M. Tian, "Can self-sacrificial leadership promote subordinate taking charge? the mediating role of organizational identification and the moderating role of risk aversion," Journal of Organizational Behavior, vol. 37, no. 5, pp. 758-781, 2016.

[22] L. Wang and L. Long, "Idiosyncratic deals and taking charge: the roles of psychological empowerment and organizational tenure," Social Behavior and Personality: An International Journal, vol. 46, no. 9, pp. 1437-1448, 2018.

[23] Q. Yang, G. Jin, J. Fu, and M. Li, "Job insecurity and employees taking charge: the role of global job embeddedness," Social Behavior and Personality: An International Journal, vol. 47, no. 4, pp. 1-12, 2019.

[24] M. F. Burnett, D. S. Chiaburu, D. L. Shapiro, and N. Li, "Revisiting how and when perceived organizational support enhances taking charge: an inverted u-shaped perspective," Journal of Management, vol. 41, no. 7, pp. 1805-1826, 2015.

[25] B. E. Ashforth and F. Mael, "Social identity theory and the organization," Academy of Management Review, vol. 14, no. 1, pp. 20-39, 1989.

[26] M. Riketta, "Organizational identification: a meta-analysis," Journal of Vocational Behavior, vol. 66, no. 2, pp. 358-384, 2005.

[27] J. B. Fuller, K. Hester, and T. Barnett, "Perceived external prestige and internal respect: new insights into the organizational identification process," Human Relations, vol. 59, no. 6, pp. 815-846, 2006. 
[28] S. E. Naumann and N. Bennett, "A case for procedural justice climate: development and test of a multilevel model," Academy of Management Journal, vol. 43, pp. 881-889, 2000.

[29] S. Tangirala and R. Ramanujam, "Employee silence on critical work issues: the cross level effects of procedural justice climate," Personnel Psychology, vol. 61, no. 1, pp. 37-68, 2008.

[30] T. Simons and Q. Roberson, "Why managers should care about fairness: the effects of aggregate justice perceptions on organizational outcomes," Journal of Applied Psychology, vol. 88, no. 3, pp. 432-443, 2003.

[31] K. W. Mossholder, N. Bennett, and C. L. Martin, "A multilevel analysis of procedural justice context," Journal of Organizational Behavior, vol. 19, pp. 131-141, 1998.

[32] K. Zhang, Z. Lv, H. F. Du, and H. Zou, "An adaptive network model to simulate consensus formation driven by social identity recognition," Complexity, vol. 11, pp. 1-13, 2020.

[33] E. A. Lind and T. R. Tyler, The Social Psychology of Procedural Justice, Plenum, New York, NY, USA, 1988.

[34] D. E. Conlon, "Some tests of the self-interest and group value models of procedural justice: evidence from an organizational appeal procedure," Academy of Management Journal, vol. 36, pp. 1109-1124, 1993.

[35] M. Tremblay, B. Sire, and D. B. Balkin, "The role of organizational justice in pay and employee benefit satisfaction, and its effects on work attitudes," Group and Organization Management, vol. 25, no. 3, pp. 269-290, 2000.

[36] N. Ramamoorthy and S. J. Carroll, "Individualism/collectivism orientations and reactions toward alternative human resource management practices," Human Relations, vol. 51, pp. 571-588, 1998.

[37] A. C. Edmondson, "Team psychological safety and learning behavior in work teams," Administrative Science Quarterly, vol. 44, pp. 350-383, 1999.

[38] M. Baer and M. Frese, "Innovation is not enough: climates for initiative and psychological safety, process innovations, and firm performance," Journal of Organizational Behavior, vol. 24, no. 1, pp. 45-68, 2003.

[39] A. Carmeli, D. Brueller, and J. E. Dutton, "Learning behaviors in the workplace: the role of high-quality interpersonal relationships and psychological safety," Systems Research and Behavioral Science, vol. 26, pp. 81-98, 2009.

[40] J. Koopmann, K. Lanaj, M. Wang, L. Zhou, and J. Shi, "Nonlinear effects of team tenure on team psychological safety climate and climate strength: implications for average team member performance," Journal of Applied Psychology, vol. 101, no. 7, pp. 940-957, 2016.

[41] H. Tajfel and J. Turner, "An integrative theory of intergroup conflict," in Social Psychology of Intergroup Relations, W. G. Austin and S. Worchel, Eds., Brooks/Cole, Monterey, CA, USA, 1979.

[42] J. C. Turner, M. A. Hogg, P. J. Oakes, S. D. Reicher, and M. S. Wetherell, Rediscovering the Social Group: A Self-Categorization Theory, Blackwell, Oxford, UK, 1987.

[43] D. M. Rousseau, "Why workers still identify with organizations," Journal of Organizational Behavior, vol. 19, pp. 217-233, 1998.

[44] B. E. Ashforth, S. H. Harrison, and K. G. Corley, "Identification in organizations: an examination of four fundamental questions," Journal of Management, vol. 34, pp. 325-374, 2008.

[45] M. A. Hogg and J. C. Turner, "Interpersonal attraction, social identification and psychological group formation," European Journal of Social Psychology, vol. 15, pp. 51-56, 1985.
[46] H. Tajfel, "The achievement of group differentiation," in Differentiation between Social Groups: Studies in the Social Psychology of Intergroup Relations, H. Tajfel, Ed., pp. 77-98, Academic Press, Cambridge, MA, USA, 1978.

[47] D. Cooper and S. M. Thatcher, "Identification in organizations: the role of self-concept orientations and identification motives," Academy of Management Review, vol. 35, pp. 516-538, 2010.

[48] J. Bartels, A. Pruyn, M. De Jong, and I. Joustra, "Multiple organizational identification levels and the impact of perceived external prestige and communication climate," Journal of Organizational Behavior, vol. 28, pp. 173-190, 2007.

[49] E. George and P. Chattopadhyay, "One foot in each camp: the dual identification of contract workers," Administrative Science Quarterly, vol. 50, pp. 68-99, 2005.

[50] N. Ramamoorthy and P. Flood, "Gender and employee attitudes: the role of organizational justice perceptions," British Journal of Management, vol. 15, no. 3, pp. 247-258, 2004.

[51] J. S. Adams, "Inequity in social exchange," in Advances in Experimental Social Psychology, L. Berkowitz, Ed., Academic Press, Cambridge, MA, USA, 1965.

[52] J. A. Colquitt, D. E. Conlon, M. J. Wesson, C. O. Porter, and K. Y. Ng, "Justice at the millennium: a meta-analytic review of 25 years of organizational justice research," Journal of Applied Psychology, vol. 86, no. 3, pp. 425-445, 2001.

[53] T. R. Tyler and S. L. Blader, "The group engagement model: procedural justice, social identity, and cooperative behavior," Personality and Social Psychology Review, vol. 7, no. 4, pp. 349-361, 2003.

[54] W. A. Kahn, "Psychological conditions of personal engagement and disengagement at work," Academy of Management Journal, vol. 33, pp. 692-724, 1990.

[55] J. R. Detert and E. R. Burris, "Leadership behavior and employee voice: is the door really open?" Academy of Management Journal, vol. 50, no. 4, pp. 869-884, 2007.

[56] J. R. DiSanza and C. Bullis, "“Everybody identifies with smokey the bear": employee responses to newsletter identification inducements at the U.S. forest service," Management Communication Quarterly, vol. 12, pp. 347-399, 1999.

[57] R. W. Brislin, "Translation and content analysis of oral and written materials," in Handbook of Cross-Cultural Psychology: Methodology, H. C. Triandis and J. W. Berry, Eds., pp. 389-444, Allyn \& Bacon, Boston, MA, USA, 1980.

[58] F. A. Mael and B. E. Ashforth, "Alumni and their alma mater: a partial test of the reformulated model of organizational identification," Journal of Organizational Behavior, vol. 13, pp. 103-123, 1992.

[59] N. Ramamoorthy and P. Flood, "Employee attitudes and behavioral intentions: a test of the main and moderating effects of individualism-collectivism orientations," Human Relations, vol. 55, no. 9, pp. 1071-1096, 2002.

[60] L. R. James, R. G. Demaree, and G. Wolf, "Rwg: an assessment of within-group interrater agreement," Journal of Applied Psychology, vol. 78, pp. 306-309, 1993.

[61] L. R. James, "Aggregation bias in estimates of perceptual agreement," Journal of Applied Psychology, vol. 67, pp. 219-229, 1982.

[62] H. He and A. D. Brown, "Organizational identity and organizational identification: a review of the literature and suggestions for future research," Group and Organization Management, vol. 38, no. 1, pp. 3-35, 2013.

[63] A. M. Grant and S. J. Ashford, "The dynamics of proactivity at work," Research in Organizational Behavior, vol. 28, pp. 3-34, 2008. 
[64] B. M. Staw and R. D. Boettger, "Task revision: a neglected form of work performance," Academy of Management Journal, vol. 33, pp. 534-559, 1990.

[65] C. McKenzie and K. James, "Aesthetic as an aid to understanding complex systems and decision judgement in operating complex systems," Emergence: Complexity \& Organizations, Special Double Issue, vol. 6, no. 1-2, pp. 32-39, 2004.

[66] S. Kelly and M. A. Allison, The Complexity Advantage: How the Science of Complexity Can Help Your Business Achieve Peak Performance, McGraw-Hill, New York, NY, USA, 1st edition, 1999.

[67] P. Poutanen, K. Siira, and P. Aula, "Complexity and organizational communication: a quest for common ground," Human Resource Development Review, vol. 15, no. 2, pp. 182-207, 2016.

[68] T. S. Bateman and J. M. Crant, "The proactive component of organizational behavior: a measure and correlates," Journal of Organizational Behavior, vol. 14, no. 2, pp. 103-118, 1993.

[69] J. M. Crant and T. S. Bateman, "Charismatic leadership viewed from above: the impact of proactive personality," Journal of Organizational Behavior, vol. 21, pp. 63-75, 2000.

[70] B. Schneider, A. N. Salvaggio, and M. Subirats, "Climate strength: a new direction for climate research," Journal of Applied Psychology, vol. 87, no. 2, pp. 220-229, 2002. 